\title{
A IMPORTÂNCIA DA MEMÓRIA NO DESENVOLVIMENTO COGNITIVO EM IDADE ESCOLAR
}

\author{
THE IMPORTANCE OF MEMORY IN COGNITIVE DEVELOPMENT AT SCHOOL AGE
}

\section{LA IMPORTANCIA DE LA MEMORIA EN EL DESARROLLO COGNITIVO EN EDAD ESCOLAR}

\author{
Carla Patrícia Vasconcelos Seixas ${ }^{1}$
}

\begin{abstract}
Resumo: Relato de experiência do projeto "O valor da memória", que procurou estimular a construção cronológica de narrativas familiares e da infância a partir do gênero biografia a fim de ampliar a capacidade de organização do pensamento lógico com alunos de $7^{\circ}$ ano. Planejaram-se 4 aulas para leitura e compreensão de biografias, elaboração e apresentação de autobiografia ilustrada, com fotos e relatos da infância, e produção textual. Como aporte teórico, recorreu-se a Vygotsky (2010, 2004), Schneuwly e Dolz (2004) e Marcuschi (2008). A partir dessa vivência didática, os alunos desfrutaram de uma rica troca de experiências da infância e do resgate de narrativas da família, além de poderem reconhecer seu próprio papel no ambiente familiar. Ademais, observouse visível progresso na construção de narrativas diversas, com ordenação cronológica de fatos.

Palavras-chave: Biografia; desenvolvimento cognitivo e social; práticas de linguagem.
\end{abstract}

\begin{abstract}
Experience report of the project "The value of memory", which sought to stimulate the chronological construction of family and childhood narratives based on the biography genre in order to expand the capacity of organizing logical thinking with 7 th grade students. Four classes were planned for reading and comprehension of biographies, elaboration and presentation of illustrated autobiography, with photos and stories from childhood, and textual production. As theoretical support, we used Vygotsky (2010, 2004), Schneuwly and Dolz (2004) and Marcuschi (2008). From this didactic experience, students enjoyed a rich exchange of childhood experiences and the rescue of family narratives, in addition to being able to recognize their own role in the family environment. Furthermore, there was a visible progress in the construction of different narratives, with chronological ordering of facts.
\end{abstract}

Keywords: Biography; cognitive and social development; language practices.

Resumen: Informe de experiencia del proyecto "El valor de la memoria", que buscó estimular la construcción cronológica de narrativas familiares e infantiles a partir del género biográfico para ampliar la capacidad de organización del pensamiento lógico con alumnos de $7^{\circ}$ grado. Se planificaron cuatro clases de lectura y comprensión de biografías, elaboración y presentación de autobiografías ilustradas, con fotografías e historias de la niñez, y producción textual. Como soporte teórico se utilizó a Vygotsky (2010, 2004), Schneuwly y Dolz (2004) y Marcuschi (2008). A partir de esta experiencia didáctica, los alumnos disfrutaron de un rico intercambio de vivencias infantiles y el rescate de narrativas familiares, además de poder reconocer su propio rol en el entorno familiar. Además, hubo un avance visible en la construcción de diferentes narrativas, con ordenamiento cronológico de los hechos.

Palabras clave: Biografía; desarrollo cognitivo y social; prácticas lingüísticas.

\footnotetext{
${ }^{1}$ Colégio Pedro II.
} 


\section{Introdução}

Segundo Vygotsky (2010), o desenvolvimento tipicamente humano depende da exposição a uma cultura, possível somente por meio da aprendizagem de crenças, valores, tradições e habilidades do grupo social ao qual a pessoa pertence. Nesse contexto, a escola torna-se essencial por favorecer a apropriação de uma prática de linguagem, que permitirá à criança interagir com o meio social. Logo, a instituição escolar deve ensinar sistematicamente o aluno a comunicar-se oralmente e por escrito, confrontando-o com os gêneros textuais aquisições acumuladas pelas sociedades no curso da história.

Observando a prática de linguagem de crianças com 11 e 12 anos, do $7^{\circ}$ ano do Ensino Fundamental II, de uma escola privada no município do Rio de Janeiro, em produções textuais escritas, aferiu-se um desempenho limitado no que tange à capacidade de organizar fatos cronologicamente. Isso evidencia insuficiência de uma habilidade essencial para o desenvolvimento de funções psicológicas superiores, dentre as quais: a organização do pensamento lógico (VYGOTSKY, 2010). Então, viu-se necessária a intervenção didática de apropriação de instrumento mediador propício para a demanda do grupo, cujo tema foi $O$ valor da memória. Para tanto, o gênero biografia emergiu como instrumento sanador dessa demanda da prática de linguagem, a fim de viabilizar a organização do pensamento lógico dos alunos.

O projeto teve como base a teoria de Vygotsky (2010) sobre a importância da aprendizagem da criança para o seu desenvolvimento mental; de Schneuwly e Dolz (2004) que, com base na concepção vygotskyana de interacionismo social, defendem que os gêneros são instrumentos, portanto a apropriação de determinada ferramenta produz desenvolvimento das capacidades individuais; e de Marcuschi (2008), de que o texto é um evento comunicativo em que ocorrem ações linguísticas, sociais e cognitivas.

Dessa forma, planejaram-se 4 aulas com a seguinte metodologia: leitura, compreensão e produção de biografias, e elaboração e apresentação de autobiografia ilustrada, com fotos e relatos da infância. Esperava-se que, assim, as turmas desenvolvessem a habilidade de ordenar fatos cronologicamente, oralmente e por escrito, aprimorando a organização do pensamento lógico, desejado para a fase do desenvolvimento.

A relevância deste projeto se deu pela promoção da aprendizagem como fonte de desenvolvimento de características humanas adquiridas, não naturalmente, mas formadas historicamente, por meio do gênero discursivo biografia, desenvolvido na oralidade e na escrita, privilegiando o valor da memória na formação do indivíduo. A proposta foi desafiadora, tendo em vista o limitado tempo para aplicar o projeto, mas também recompensadora em testemunhar o desenvolvimento cognitivo e social do grupo.

\section{Metodologia}

O projeto "O valor da memória" foi realizado em duas turmas de $7^{\circ}$ ano do Ensino Fundamental II, 3171 e 3172, de uma escola privada na Zona Norte do Rio de Janeiro, no componente curricular Redação, nos meses de fevereiro e março de 2020, antes da suspensão das aulas presenciais devido à pandemia de Covid-19.

Iniciado o ano letivo de 2020, logo nos primeiros encontros com as turmas 3171 e 3172 , observou-se, dentre inúmeras demandas típicas do desenvolvimento psíquico da faixa etária, uma limitação de alguns estudantes na capacidade de ordenar cronologicamente fatos em produções textuais escritas. $\mathrm{Na}$ oralidade, essa prática de linguagem não era tão comprometida, no entanto, ao redigir um texto em que fosse necessária essa capacidade, os alunos não conseguiam construir satisfatoriamente uma linha temporal para os 
acontecimentos, apontando uma necessidade de uma intervenção didática que propusesse meios para a desenvolução de organização do pensamento lógico.

Nesse sentido, considerando o gênero como um instrumento mediador que, por um lado, depara-se com o objeto social, elaborado pelas gerações predecessoras, e, do outro, o sujeito (SCHNEUWLY; DOLZ, 2004), procurou-se alargar as experiências possíveis desse grupo de estudantes com a linguagem por meio do projeto $O$ valor da memória, cujo objetivo foi amplificar a capacidade de organização do pensamento lógico dos alunos a partir da ordenação cronologicamente dos fatos de sua infância.

Ademais, considerada a perspectiva de interacionismo social de que a escola seja um ambiente propício à aprendizagem de habilidades adquiridas socialmente (VYGOTSKY, 2004), foram planejadas 4 aulas para que se pudesse trabalhar uma unidade do discurso - o gênero biografia - de modo a propiciar a apropriação desse instrumento como ferramenta de desenvolvimento de capacidades individuais (SCHNEUWLY; DOLZ, 2004), nesse contexto de ordenar fatos cronologicamente.

Para a prática da vivência didática planejada, inicialmente foi solicitado aos alunos que pesquisassem biografias de personalidades da contemporaneidade ou não, mas que fossem de pessoas que gostariam de se informar mais sobre sua vida, carreira profissional ou artística. Então, para o primeiro dia do planejamento, visando ao aperfeiçoamento da competência leitora e da produção oral, como postulam Schneuwly e Dolz (2004), os estudantes que realizaram a pesquisa leram para a turma as biografias selecionadas, e muito se soube sobre a trajetória de vida e profissional de youtubers, de jogadores de futebol, de grupos musicais de K-pop, de artistas de cinema e das tão populares séries de serviços de streaming. Os diálogos em aula sobre as biografias possibilitaram um espaço para a troca de conhecimento de mundo, de gostos e de interesses pessoais e até mesmo para a divulgação do trabalho profissional e artístico de personalidades antes desconhecidas por alguns.

$\mathrm{Na}$ sequência do planejamento, em uma aula seguinte, foi solicitado aos discentes para que, em grupos, observassem pontos em comuns na forma como as biografias eram organizadas: por qual ponto eram iniciadas, que tipo de informações eram relevantes no desenvolver do texto, como eram finalizadas, qual a sua extensão, em quais meios poderiam ser veiculadas, qual seria sua finalidade e quem seriam os interlocutores envolvidos na produção e recepção do gênero. Assim, aos poucos o grupo apropriava-se daquela ferramenta, compreendendo os esquemas da sua utilização e de que forma poderiam organizá-la.

Como atividade extraclasse após o segundo dia de execução do projeto, os estudantes deveriam selecionar em revistas, jornais ou na internet uma entrevista de outra personalidade histórica para que pudessem embasar a biografia que deveriam redigir. Dessa forma, a partir das informações fornecidas pelo entrevistado, dever-se-ia produzir por escrito uma biografia da pessoa selecionada. Além disso, para as duas últimas aulas dessa sequência, as turmas deveriam levar individualmente fotografias de fases distintas da infância, com a presença ou não de familiares, para a construção de uma autobiografia ilustrada.

Assim, a última atividade proposta, programada para as aulas 3 e 4 do projeto, foi a confecção da autobiografia ilustrada. Cada aluno deveria colar as fotografias selecionadas de sua infância, ordenadas cronologicamente em uma cartolina e, abaixo de cada imagem, redigir legendas que narrassem brevemente o fato retratado. $\mathrm{O}$ objetivo dessa prática foi favorecer a observação da lógica da construção da linha temporal dos acontecimentos para a compreensão da narrativa de sua infância. A elaboração das autobiografias ilustradas em grupo, apesar de serem documentos pessoais, permitiu a troca de experiências vividas em sua vida, o compartilhamento de narrativas familiares, a cooperação entre os alunos para a composição de cartazes e de legendas que fossem inteligíveis aos colegas e o reconhecimento do próprio papel 
no contexto familiar ao propor uma oportunidade para a produção textual oral e escrita. Alguns registros podem ser observados nas figuras a seguir.

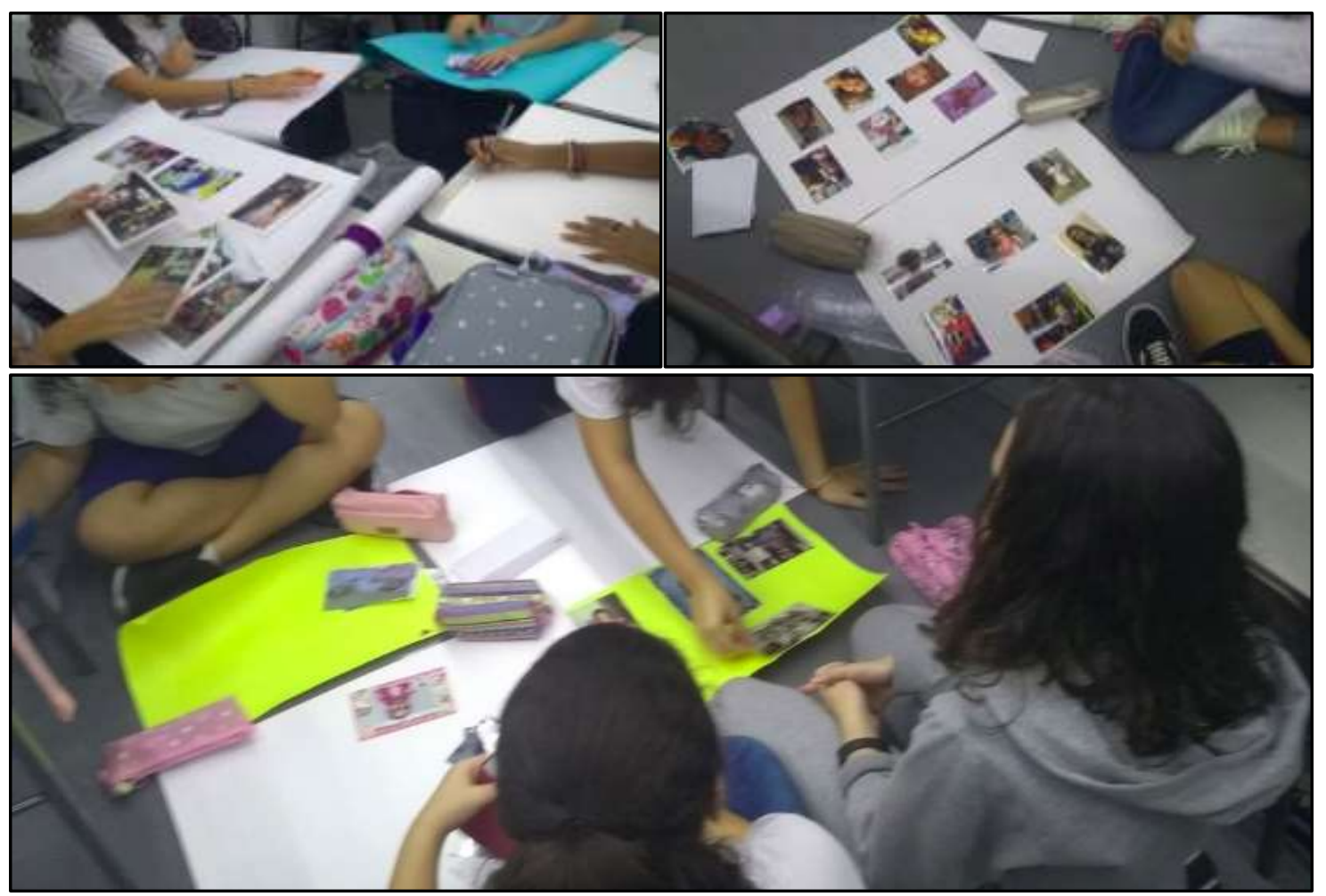

Figura 1: Construção da autobiografia ilustrada na turma 3171 - Fonte: Elaboração própria
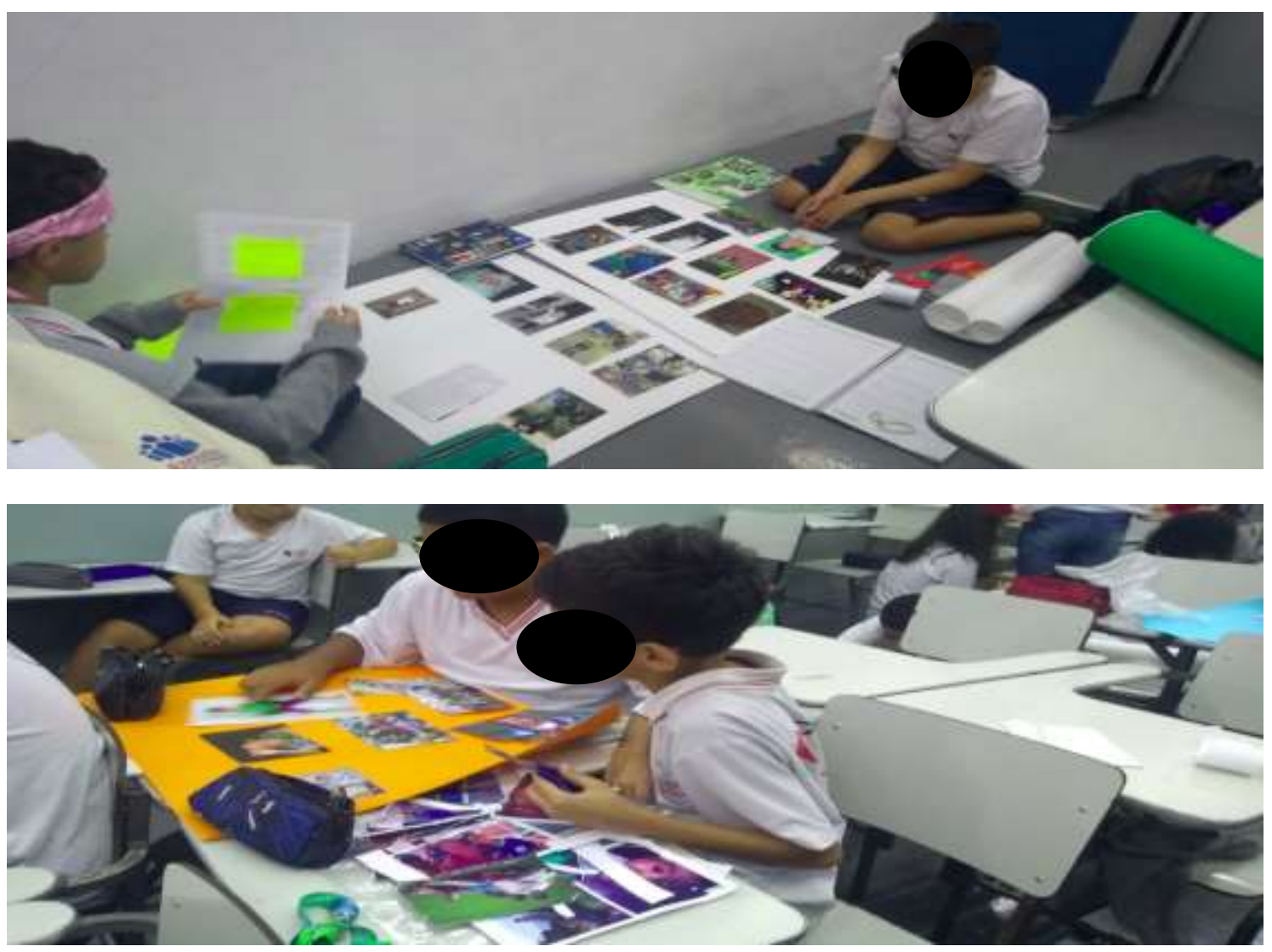

Figura 2 - Construção da autobiografia ilustrada na turma 3172 - Fonte: Elaboração própria 


\section{Discussão}

Segundo a teoria sociointeracionista de Vygotsky (2010, 2004), a aprendizagem desperta os processos de desenvolvimento, que se tornam parte das funções psicológicas já enraizadas no sujeito. Nesse sentido, é por meio da interação com pessoas em um ambiente e/ou da atuação cooperativa entre indivíduos que os processos internos de desenvolvimento são operados, visto que são irrompidas pela aprendizagem. Nas palavras do psicólogo, “[...] a aprendizagem é um momento intrinsecamente necessário e universal, para que se desenvolvam na criança essas características humanas não naturais, mas formadas historicamente" (VYGOTSKY, 2010, p. 115). Por isso, a escola torna-se um ambiente fundamental para favorecer o desenvolvimento humano, já que esse processo é deflagrado e impulsionado pela aprendizagem e dela resulta.

É na escola que se deve ter contato com a história dos povos, sua cultura, sua língua; conhecer as diversas ciências já construídas pela humanidade; entender o funcionamento e a atividade de preservação do planeta onde vivem; compreender como se dão processos cotidianos de sua cultura; apreciar literatura, artes, música e toda forma de expressão humana; conscientizarse dos direitos e dos deveres de todas as pessoas em sua sociedade; conseguir se expressar por meio da linguagem e das artes em geral; resolver problemas diversos da vida prática e uma série de outras noções e de outras práxis tão necessárias para a sua interação social, dentro e fora dos muros escolares, a fim de que a aprendizagem desperte seu desenvolvimento individual.

Para Vygotsky (2004), as alterações qualitativas produzidas ao longo do desenvolvimento humano são condicionadas previamente pela aprendizagem, ou seja, o desenvolvimento em idade escolar só é possível mediante o ensino e aprendizagem intencionais, no contexto escolar, em que professor e aluno estejam engajados em situações dessa finalidade. No que tange às práticas de linguagem, inicialmente sua apropriação se dá em um contexto familiar, mas as que se concernem à escrita e à oralidade formal ocorrem principalmente em contexto escolar, onde os discentes são conduzidos ao entendimento das demandas de linguagem de produção e de compreensão (SCHNEUWLY; DOLZ, 2004).

Ao considerar que para o interacionismo social a construção de funções psicológicas superiores - memória, consciência, percepção, atenção, fala, pensamento, vontade, formação de conceitos e emoção (VYGOTSKY, 2004) - dependem da interação do indivíduo com sua sociedade e da utilização da linguagem, Schneuwly; Dolz (2004, p. 40) propõem que "[...] o desenvolvimento da autonomia do aprendiz é, em grande parte, consequência da mestria do funcionamento da linguagem em situações de comunicação". Assim, o objetivo primordial do ensino deve ser "instrumentalizar o aprendiz", nas palavras dos autores, com ferramentas que os possibilitem descobrir os critérios sociais para cada prática comunicativa, bem como o emprego de unidades linguísticas nas aplicações cotidianas.

É a partir dessas premissas que emergiram este e outros fazeres didáticos nas turmas de $7^{\text {o }}$ ano de um colégio privado, localizado na Zona Norte do Rio de Janeiro, e no qual se embasam outras práticas educativas no ensino de língua materna, no Ensino Fundamental II, ao longo da docência. Então, mediante a observação da necessidade de ampliar uma habilidade cognitiva dos alunos das turmas 3171 e 3172, a saber, a ordenação cronológica de fatos, resultante da organização do pensamento lógico de crianças com 11 e 12 anos, é que o projeto "O valor da memória" foi elaborado e realizado.

As atividades executadas - seleção individual e leitura de biografias em turma, produção de texto biográfico a partir de entrevista pesquisada pelo aluno e composição de autobiografia ilustrada, com fotografias e pequenos relatos da infância - foram projetadas de forma a explorar a oralidade, a leitura e a produção textual individual e coletiva, de modo a valer-se dos recursos linguísticos que os estudantes já possuíam e que utilizavam 
espontaneamente no dia a dia para o apoderamento de novos usos da língua materna, viabilizando práticas sociais diversificadas. Assim, a sequência didática viabilizou experiências de aprendizado que favorecessem a aquisição de recursos comunicativos que amplificassem a interação dos alunos com o mundo ao seu redor (BORTONI-RICARDO, 2004) e de práticas de linguagem que os permitissem a se desenvolver cognitivamente.

Inclusive, a montagem da autobiografia ilustrada, proposta para ser feita em aula, levou em consideração as possibilidades de troca entre alunos durante a sua preparação. Mesmo sendo uma atividade pessoal, de teor individual, a recomendação de que fosse realizada em grupos oportunizou a prática da oralidade enquanto os estudantes contavam as histórias ligadas à cada fotografia, a colaboração na produção das legendas das fotos - os pequenos relatos acerca das situações retratadas nas imagens -, o compartilhamento de experiências da infância e da família, o integração de novos alunos e dos que não possuíam muita proximidade social com o restante da turma e o reconhecimento do próprio papel dentro do contexto familiar e social. Esses ganhos, somados ao ensino direcionado do gênero biografia, suscitaram a apropriação de novas habilidades cognitivas e sociais, necessárias ao desenvolvimento dos indivíduos.

Nesse contexto, salienta-se que a linguagem humana é catalisadora da aprendizagem, já que é por meio dela que se dá o intercâmbio social e o pensamento generalizante. Em outras palavras, além de a linguagem servir de comunicação entre seres humanos, ela também serve para simplificar e categorizar as experiências do indivíduo, mediando suas relações com o mundo (OLIVEIRA, 1992). Considerando que a língua seja uma atividade sociointerativa de base histórica e cognitiva (MARCUSCHI, 2008), a escola deve focar no ensino de língua materna intermediado por textos, considerando para além dos seus aspectos formais: suas possibilidades de uso, de enriquecimento e de transformação. Como lembra Marcuschi (2008, p. 80), a definição de Beaugrande, "é essencial tomar o texto como um evento comunicativo no qual convergem ações linguísticas, cognitivas e sociais". Logo, a proposta escolar com textos não se deve limitar à análise de classe de palavras, de sintaxe, de ortografia e afins, antes deve contemplar toda a complexidade envolvida na riqueza de aspectos que os formam.

Em continuidade, Marcuschi (2008) pondera que, nas operações linguísticas, o indivíduo lida mais do que com o uso elementar de regras, sejam estruturais (sintáticas) ou de formas (morfológicas). O que está em jogo é uma gama de sistemas e subsistemas que concedem aos falantes comunicarem-se por meio da escrita ou da oralidade, selecionando e indicando múltiplos sentidos por meio da linguagem utilizada. Por isso, a partir das habilidades primárias para o uso da linguagem, a escola deve considerar o que já está disponível ao aluno para contribuir para que se desenvolva ainda mais e para outras demandas sociocomunicativas do seu contexto.

À vista disso, o trabalho com gêneros na escola, apoiado na concepção vygotskiana, pode ser considerado um instrumento psicológico que visa ao desenvolvimento das capacidades do indivíduo (SCHNEUWLY; DOLZ, 2004). A perspectiva é de que o gênero seja um instrumento mediador da atividade entre o sujeito e o objeto sobre o qual age ou a situação na qual age, mediante a apropriação dessa ferramenta para que sejam provocados novos conhecimentos e saberes no indivíduo, que, segundo Schneuwly e Dolz (2004), abrem novas possibilidades de ações, que as sustenta e as orienta.

Sob essa ótica, a apropriação do gênero biografia por parte dos estudantes das turmas 3171 e 3172 oportunizou o apuramento da habilidade de organizar acontecimentos em uma linha temporal, respeitando a ordem dos eventos. Vale ressaltar que os gêneros são socialmente elaborados, ou seja, resultam das experiências de gerações predecessoras (SCHNEUWLY; DOLZ, 2004). Portanto, a apropriação do gênero biografia não só impulsionou o desenvolvimento da habilidade em questão, como também enriqueceu o conjunto de recursos comunicativos dos estudantes, tão necessários para desempenharem bem e com segurança as tarefas linguísticas da vida em sociedade (BORTONI-RICARDO, 2004). 


\section{Considerações finais}

A partir da perspectiva sociointeracionista de Vygotsky (2010, 2004), o projeto "O valor da memória" foi concretizado nas turmas 3171 e 3172, de uma escola privada na Zona Norte do Rio de Janeiro, no início do ano letivo de 2020, ainda quando as atividades escolares eram presenciais, como intervenção diante da observação da limitação dos alunos em ordenar cronologicamente os fatos, o que insinuava a defasagem de organização do pensamento lógico por crianças de 11 e 12 anos.

A sequência didática contou com o gênero biografia como instrumento mediador que pudesse favorecer o desenvolvimento cognitivo de crianças em idade escolar, a partir das práticas de oralidade, de leitura e de escrita de textos biográficos de personalidades em evidência na sociedade e das próprias narrativas familiares e da infância. Então, foram planejadas 4 aulas, de dois tempos cada, com a seguinte metodologia: leitura, compreensão e produção de biografias, e elaboração e apresentação de autobiografia ilustrada, com fotos e relatos da infância. Dessa forma, as turmas puderam desenvolver a habilidade de ordenar fatos cronologicamente, oralmente e por escrito, aprimorando a organização do pensamento lógico esperado para a fase do desenvolvimento.

Como embasamento teórico, o processo didático dispôs de teorias como a de Vygotsky (2010) sobre a importância da aprendizagem da criança para o seu desenvolvimento mental; de Schneuwly e Dolz (2004) que, com base na concepção vygotskyana de interacionismo social, defendem que os gêneros são instrumentos, portanto a apropriação de determinada ferramenta produz desenvolvimento das capacidades individuais; e de Marcuschi (2008) sobre o texto como um evento comunicativo em que ocorrem ações linguísticas, sociais e cognitivas.

Os ganhos desse projeto foram inúmeros, desde a desenvolução de novas práticas de linguagem para interação com o meio em que vivem, por meio da apropriação do gênero biografia e da troca de experiências de linguagem entre os estudantes, até mesmo o desenvolvimento de habilidades próprias para o progresso lógico de raciocínio dos estudantes.

\section{Referências}

BORTONI-RICARDO, S. M. Educação em língua materna: a sociolinguística em sala de aula. São Paulo: Pontes, 2004.

BORTONI-RICARDO, S. M. Falar, ler e escrever em sala de aula. São Paulo: Pontes, 2008.

MARCUSCHI, L. A. Produção textual análise de gêneros e compreensão. São Paulo: Pontes, 2008.

OLIVEIRA, M. K. Vygotsky e o processo de formação de conceitos. In: LA TAILLE, Y.; OLIVEIRA, M. K.; DANTAS, H. (Org.). Piaget, Vygotsky, Wallon: teorias psicogenéticas em discussão. São Paulo: Summus, 1992. p. 23-34.

SCHNEUWLY, B. DOLZ, J. Gêneros orais e escritos na escola. Campinas: Mercado das Letras, 2004.

VYGOTSKY, L. S. Sobre os sistemas psicológicos. In: VYGOTSKY, L. S. Teoria e método em psicologia. 3. ed. São Paulo: Martins Fontes, 2004. p. 103-135.

VYGOTSKY, L. S. Aprendizagem e desenvolvimento intelectual na idade escolar. In: LURIA, A. R.; LEONTIEV, A. N. Linguagem, desenvolvimento e aprendizagem. Trad. M. P. Villalobos. 11 ed. São Paulo: Ícone, 2010. p. 103-117. 


\section{Sobre a autora}

Carla Patrícia Vasconcelos Seixas. Possui Licenciatura Plena em Letras (Português Espanhol) pela Fundação Educacional Campograndense (2010) e Pós-graduação em Língua Portuguesa pelas Faculdades Souza Marques (2014). Professora da Rede Municipal de Teresópolis e do Centro Educacional da Lagoa Intercultural School. Mestranda do Programa de Mestrado Profissional em Práticas de Educação Básica no Colégio Pedro II e pesquisadora no Grupo de Estudos e Pesquisas em Língua(gem)e Projetos Inovadores na Educação Básica, certificado pela Reitoria de Pós-Graduação, Pesquisa, Extensão e Cultura do Colégio Pedro II. E-mail: carlaseixas.prof@gmail.com. 